Revista Temas Socio Jurídicos

Vol. $37 \mathrm{~N}^{\circ} 75$ Julio - Diciembre de 2018

pp. $35-67$

ISSN: 0120-8578

ISSN electrónico: 2590-8901

\title{
LA DELINCUENCIA JUVENIL COMO HERRAMIENTA DE SATISFAC- CIÓN DEL DESEO DE RECONOCIMIENTO COLECTIVO
}

\author{
Sérgio Rodrigues de Souza ${ }^{1 *}$ \\ Recibido: Octubre 20 de 2018 \\ Aprobado: Diciembre 1 de 2018
}

\begin{abstract}
RESUMEN
Este artículo-ensayo aborda la temática de investigación que involucra la problemática de la delincuencia juvenil como herramienta de satisfacción del deseo de reconocimiento colectivo. Es parte de una tesis posdoctoral en Psicología Social y busca presentar cómo la delincuencia juvenil ha sido utilizada como herramienta de satisfacción del deseo de reconocimiento colectivo por los adolescentes. Se trata de una investigación bibliográfica fundamentada en estudios clásicos sobre el tema, que realiza una búsqueda empírica de respuestas junto a adolescentes, a través de entrevistas informales y observación participante. Se caracteriza como un ensayo factual, exploratorio y analítico, quetiene como método de interpretación el analítico-sintético/sintético-analítico. Su objetivo general es presentar un análisis del problema que conduce a los adolescentes a cometer actos delictivos, como forma de alcanzar reconocimiento de sus coetáneos. Tiene como objetivo específico analizar las consecuencias de la delincuencia. Las conclusiones a las que se llega es que no se pueden confundir los sentimientos naturales de un adolescente con los deseos narcisistas y neuróticos motivados por una necesidad de corrección de una falla educativa. Querer ser mirado y admirado por sus cualidades, sus méritos personales y científicos es un derecho subjetivo natural de cualquier ser humano en cualquier tiempo y espacio. Aquello que no puede ser admitido es que tal condición sea utilizada como explicación de la agresividad cada vez mayor que aqueja a la sociedad, al tornarse esta como víctima de las manos de adolescentes infractores.
\end{abstract}

$1^{*}$ Profesor Licenciado en Filosofía y Sociología. Psicoanalista. Pos-doctorando en Psicología Social de la Universidad Kennedy. (Buenos Aires - AR). Este ensayo es parte de mi tesis posdoctoral, con defensa programada para noviembre de 2018. 
Palabras clave: Delincuencia juvenil, Herramienta de satisfacción, Deseo de reconocimiento colectivo.

\title{
JUVENILE DELINQUENCY AS A TOOL TO SATISFY THE DESIRE FOR COLLECTIVE RECOGNITION
}

\begin{abstract}
This article-essay deals with the subject of research that involves the problem of juvenile delinquency as a tool to satisfy the desire for collective recognition. It is part of a postdoctoral thesis in Social Psychology and seeks to present how juvenile delinquency has been used as a tool to satisfy the desire for collective recognition by adolescents. It is a bibliographical research based on classic studies on the subject and an empirical search of answers with adolescents, through informal interviews and participant observation. It is characterized as a factual, exploratory, analytical essay, having as analytical-synthetic-synthetic-analytical method. Its general objective is to present an analysis of the problem that leads adolescents to commit criminal acts, as a way to achieve recognition of their peers. Its specific objective is to analyze the consequences of crime. The conclusions reached is that you can not confuse the natural feelings of a teenager with narcissistic and neurotic desires motivated by a need to correct an educational failure. Wanting to be watched and admired for its qualities, its personal, scientific merits is a natural subjective right of any human being in any time and space. What can not be admitted is that such a condition is used as an explanation for the increasing aggressiveness that society is becoming a victim through the hands of adolescent offenders.
\end{abstract}

Keywords: Juvenile delinquency, Satisfaction tool, Desire for recognition collective.

\section{A DELINQUÊNCIA JUVENIL COMO FERRAMENTA DE SATISFAÇÃO DO DESEJO DE RECONHECIMEN- TO COLETIVO}

\section{RESUMO}

Este artigo-ensaio aborda o tema de pesquisa que envolve o problema da delinquência juvenil como ferramenta de satisfação do desejo de reconhecimento coletivo. Faz parte de uma teses de pós-doutorado em Psicologia Social e busca apresentar como a delinquência juvenil tem sido utilizada pelos adolescentes como ferramenta para satisfazer o desejo de reconhecimento coletivo. Trata-se de uma pesquisa bibliográfica baseada em estudos 
clássicos sobre o tema, que realiza uma busca empírica de respostas de adolescentes, por meio de entrevistas informais e de observação do participante. Caracteriza-se como um ensaio exploratório e analítico, que usa o método de interpretação analítico-sintético/sintético-analítico. O objetivo geral deste trabalho é apresentar uma análise do problema que leva adolescentes a cometer atos criminosos, como forma de obter reconhecimento de seus pares. Seu objetivo específico é analisar as consequências da delinquência. A conclusão alcançada é que não devemos confundir os sentimentos naturais de um adolescente com os desejos narcisistas e neuróticos motivados por uma necessidade de correção de falhas educativas. Querer ser visto e admirado por suas qualidades, seus méritos pessoais e científicos é um direito subjetivo natural de qualquer ser humano em qualquer tempo e espaço. O que não pode ser admitido é que essa condição seja usada como uma justificativa da agressividade que aflige a sociedade, uma vez que se torna vítima das mãos de adolescentes infratores.

Palavras-chave: Delinquência juvenil; Ferramenta de satisfação; Desejo de reconhecimento coletivo.

\section{INTRODUCCIÓN}

En la naturaleza existen algunas criaturas que son de hábitos solitarios, viven en la más completa soledad, pero se reúnen por ocasión del periodo reproductivo. Estas especies son pocas porque, en su mayoría, subsisten siempre en medio de bandos mayores; esta situación de vivencia les garantiza protección contra enemigos mayores, más crueles y poderosos. Luego, la condición de sociabilidad funciona como un mecanismo de protección de la vida individual y social. Una cosa que no debe ser olvidada es que los animales siguen instintos primitivos, desarrollados hace muchos millares de años, por tanto, su acción es una repetición totalmente inconsciente del proceso que los mueve hasta aquella acción en particular; en conclusión, no ejecutan el pensamiento más simple.

De manera distinta a los animales irracionales, el hombre es una criatura solitaria y se une a otros por conveniencia o necesidad. A lo largo de su proceso evolutivo y en especial después del surgimiento y desarrollo de su corteza, comenzó a analizar con mucha profundidad sus acciones con relación a los demás que están cerca de él. Por causa de las extremadas limitaciones físicas a que fue sometido el ser humano por la naturaleza, se vio obligado a unirse a sus compañeros con el fin de garantizar victorias en las batallas más complejas como la caza, las guerras y la construcción de un medio para imponer respeto: algo que fungiera como un elemento inhibitorio de ataques por parte de sus enemigos y/o rivales.

La convivencia grupal fue suscitando el nacimiento de otros tipos de comportamientos; estos, a su vez, dieron origen a costumbres que se transformaron en cultura y más adelante en tradición. Cuando se llegó a este 
punto de convergencia, todo aquello se transformó en necesidad biológica y antropológica; una condición sin la cual ya no le era posible al individuo sentirse feliz, porque fue infundido en su espíritu el miedo de que la condición de soledad y aislamiento pudiese dejarlo vulnerable a fuerzas externas, situadas fuera de su dimensión de conocimiento cognitivo e intelectual. Por tanto, para hacer parte del grupo era necesario que fuese reconocido por los integrantes de este como alguien de valor para el grupo; tenía que probar su coraje y relevancia ante pruebas desafiantes. Aquí ya se tiene la primera convicción de que el colectivo se tornó más poderoso que el individuo. Esto ya confiere elementos para defender con seguridad que el reconocimiento colectivo no se efectúa por aquello que el individuo es, sino por aquello que es capaz de proporcionar al grupo. Ayuda, de igual forma, a comprender porqué las personas que son aisladas de los colectivos tienden a ser depresivas y, algunas, toman la decisión de suicidarse. El impedimento de hacer parte del colectivo les sugiere que son incapaces de contribuir a la manutención o crecimiento del mismo; es decir, son seres que carecen de valor. Cabe traer a colación que los miembros del colectivo de infractores procuran ejecutar más y más acciones delictivas que propician el aumento del capital del grupo. Este comportamiento se debe a que estos aglomerados son gestionados como empresas que componen la bolsa de valores y los participantes tienen la obligación de contribuir para la elevación de su capital de trabajo, utilizando la máxima de que cada miembro vale en la medida de lo que produce; entonces, si no produce nada no vale nada y esto es un golpe porque la mayoría de estos adolescentes provienen de hogares donde son tratados como peso muerto, hecho que colabora en la interpretación de la violencia neurótica utilizada por los delincuentes en sus acciones y que, aún, a la menor resistencia de la víctima es motivo para la deliberación despótica de actos violentos hasta con la muerte inminente de quien presente resistencia.

El tamaño de la carga de odio, dirigida contra todo y contra todos, no es originaria de su condición de vida, es producto de su carga catexial de negación originaria de sus padres y otras criaturas enojadas e inconformes con sus situaciones sociales que acaban descargando sobre ellos toda esta fuerza desmedida, como si los niños y niñas fuesen culpadas por su existencia y por sus condiciones de vida. En consecuencia, la sociedad es quien termina cargando toda la culpa, cuando sobre ella recae toda la violencia que ella misma produce, al no cumplir su parte en el contrato social. En adición, esta situación de conflictos entre los delincuentes y la sociedad termina por proporcionar subsidios intelectuales, explicaciones para los males que asolan la sociedad, estos entendidos como medios que ayudan en la comprensión de las fuerzas subjetivas y objetivas de los colectivos que imperan sobre los adolescentes, transformándolos en criaturas insanas y sin una opción que no sea la de la utilización de la fuerza bruta desmedida para alcanzar sus objetivos. No ser nada y tener una expectativa de superación en la vida es una cosa; no ser nada y permanecer 
todos los días de la vida de esta forma, es ultrajante y este conglomerado de delincuentes crea una idea de que su grupo hará un cambio en todo el sistema de valores; crea un mecanismo de lavado cerebral tan sofisticado que todos allí pasan a creer que no hay solución fuera de aquel espacio y que no son ni podrán llegar a ser alguien de valor una vez que estén sin la protección del mismo.

\section{PROBLEMA DE INVESTIGACIÓN}

Esta tesis se dedicó a descubrir las causas objetivas y subjetivas que conducen a los adolescentes a cometer actos delictivos, como forma de ser reconocidos por sus pares. Esta situación singular ha provocado grandes discusiones en todos los medios vinculados, directa o indirectamente, a la seguridad pública, y por más que se dedique a encontrar una solución que disminuya el problema, esto parece no estar siendo alcanzado. Así que se toma como pregunta orientadora de este ensayo: ¿Qué factores ejercen influencia para que los adolescentes busquen la delincuencia como una herramienta de satisfacción de sus deseos de reconocimiento colectivo?

\section{HIPÓTESIS DE TRABAJO}

Este documento parte de la siguiente hipótesis: el hombre es un ser que se agrega a otros por conveniencia o por necesidad; no obstante, los adolescentes, dado su condición de inmadurez psicológica y personológica, necesitan ser reconocidos para sentirse seguros y así poder desarrollar su personalidad de la manera más sensible. Al no encontrar tal apoyo en sus padres lo buscan en sus coetáneos que crean rituales de pasaje, obligándolos a ejecutar acciones que desafían el orden y las costumbres tradicionales. En su inicio, tales hechos nacen como bromas; sin embargo, en la medida que se van repitiendo, se transforman en transgresiones legales, llegando a actitudes delincuenciales de elevado riesgo.

El colectivo crea elementos de valorización para estas actitudes, los cuales son interpretados por los chicos como actitudes de reconocimiento y sin percibirlo terminan presos en una red de conflictos con la ley. Esta red es marcada por su estadio de salud psicológica y por el abuso de sus compañeros.

\section{ESTRATEGIA METODOLÓgICA}

Con la intención de alcanzar los resultados y partiendo de los objetivos planeados, se llevó a cabo una búsqueda por medio de métodos teóricos; se eligió el método histórico-lógico, que se empleó para profundizar en las principales concepciones de las regularidades y contradicciones esenciales como una de las fuentes del proyecto. Se utilizó el método analítico-sintético que se aplica en todo el proceso de estudio histórico y diagnóstico sociológico, usando el método de representación social, en el que se avanzó por el análisis a la integración sistemática entre causa y efecto, utilizando las síntesis en la estructuración del proyecto aplicándolas so- 
bre el objeto de estudio; se empleó el inductivo-deductivo para adecuar los hechos observados, los resultados del análisis de los instrumentos aplicados, para establecer juicios, revelar regularidades y acercarse a conclusiones; también el sistémico-estructural para el estudio de aspectos relacionados con el carácter sistémico de los valores; y por último, nos servimos de la orientación general.

En esta investigación se asume el enfoque dialéctico-materialista como método general de la ciencia que integra lo cuantitativo y lo cualitativo; este revela la relación entre los aspectos internos y externos del objeto, causas y consecuencias, y tiene la práctica como principio y fin de conocimiento. Se apoya en métodos específicos de la investigación científica de los niveles teórico y empírico.

\section{DISCUSIÓN Y RESULTADOS}

El hombre es una criatura que vive en medio de otros iguales a él y, también, en medio de personas diferentes que piensan de forma distinta a él; aparentemente se siente feliz así, demostrando una apariencia que siempre fue el modo en el que ha sido visto por todos. Aristóteles de Estagira (384322a.C.) llegó al extremo de afirmar que los seres humanos sienten ansia de vivir en sociedad. La lectura del filósofo es equivocada porque el ansia que el hombre demuestra por vivir en sociedad, es la oportunidad demostrada por vivir en la ciudad, en la pólis, porque esto les confería la condición de ciudadanos y todos los derechos de reconocimiento que tal título les proporcionaba. Tenemos en cuenta que no fue hecho por el filósofo un análisis acerca de las privaciones que la vida dentro de los muros de la ciudad provocaba a los ciudadanos, porque las más terribles privaciones aún eran mejores que vivir en la más completa oscuridad, aislado de todo y de cualquier derecho, sin ningún tipo de reconocimiento, como era la vida de aquellos que estaban fuera de los muros de la ciudad. La vida dentro de los muros de la ciudad antigua, aunque fuese pesada y marcada por un elevado costo, garantizaba al individuo cierta seguridad.

Friedrich Nietzsche (2004) se refiere a la vida en sociedad como un retroceso en la condición instintiva. Para él, la convivencia social priva a los individuos de su fuerza natural, de su espíritu de independencia y crea, con esto, un doliente psíquico, un retrógrado, un miembro de las masas; esto iría en contra de su naturaleza libre y salvaje que, al no satisfacerla, provoca una lucha continúa, arañando las paredes de su espíritu; tal condición conduciría a actos agresivos contra sus compañeros. Freud (2006) y Konrad Lorenz (1973) van a concordar, ipsis litteris, con esta afirmación; sin embargo, nos hemos encontrado con una cuestión de amplia complejidad para explicar por qué los actos más violentos son cometidos por individuos que conforman pandillas. ¿Ocurre en estas ocasiones una supresión de los valores humanísticos adquiridos o se trata de una libre manifestación de su naturaleza tal cual es? 
En oposición a un espíritu deseoso de libertad existe un espíritu deseoso de poder que solamente puede ser alcanzado por la unión con los pares; siempre va a haber personas sádicas que están dispuestas a unirse a otros aun más sádicos y formar los colectivos compuestos por delincuentes en potencia que, una vez reunidos bajo un mismo ideal, crean códigos de valores conflictivos con la justicia y el bienestar de todos, como el derecho de vivir en seguridad, garantizado esto en la carta constitucional de cada nación.

No se puede confundir los sentimientos naturales de un adolescente con los deseos narcisistas y neuróticos motivados por una necesidad de corrección de una falla educativa. Querer ser mirado y admirado por sus cualidades, sus méritos personales y científicos es un derecho natural de cualquier ser humano. Aquello que no puede ser admitido es que tal condición sea utilizada como explicación de la agresividad cada vez mayor que la sociedad padece como víctima de parte de adolescentes infractores.

Los discursos libertarios que ponen como formas confrontación la autonomía con la heteronomía fueron una de las causas más agresivas que acabó por conducir a la adolescencia y a la juventud al mundo de la violencia. Es solamente en la cabeza de un anarquista sociópata que tal condición puede tener sentido. Sin embargo, encontró voces muy poderosas que no perdieron tiempo en defender tal idea como verdadera. Cuando Emile Durkheim (1858-1917), em su obra El Suicidio (1897), elabora los términos autonomía $y$ heteronomía posee en sus fundamentos epistemológicos mucho de la doctrina kantiana, en donde la primera estaba vinculada a un respeto a las doctrinas sociales, conceptos ya fundamentados en las doctrinas orientales; la heteronomía estaba vinculada a una dependencia psicopatológica que debería ser convertida en un principio de bienestar social porque de otra forma podría conducir a la anomia, un estadio psicológico semejante a un estadio vegetal, que no es aceptado por nuestra condición de vinculación a la vida gregaria. Así las cosas, no existe en el concepto durkheimiano relación de antagonismos entre las tres instancias, demostrando que son muy independientes, cada cual con su campo de inferencias y necesidades de intervención directa o indirecta.

La vida en sociedad creó necesidades que antes no se hacían presentes en la psiquis del individuo; por lo tanto, no se perjudicaba su economía mental, vivía feliz sin ellas hasta el momento en que aparecen y se tornan parte de su cultura, siendo transmitidas a las generaciones futuras como parte de algo que siempre estuvo allí a la espera de una aceptación como hecho dado. Uno de estos elementos, que fueron incorporados al sistema psíquico humano a partir del proceso de civilización, fue el deseo de reconocimiento por sus pares más próximos, aquellos que forman un círculo en torno a él y que pueden ser llamados "colectivo". Se toma este concepto de Anton Makarenko (1957), que lo clasificaba como un grupo pequeño, circunspecto. En este entendimiento del pedagogo ucraniano, 
este grupo podría dar al individuo adolescente algún empoderamiento espiritual por medio del cual él podría volverse mejor, reconociéndose en su totalidad como ser humano. Existe un elemento que representa el eje centralizador que caracteriza la manutención de tales grupos; este es el vínculo afectivo que se crea entre sus miembros, consecuentemente el leitmotiv sería el deseo de superación y aceptación como un hombre de valor para sus coetáneos. Esta conceptualización de colectivo y toda la creencia en la bondad espontanea del género humano sigue una idea pedagógico-sociológica fundamentada sobre bases románticas rousseaunianas que pueden tener un funcionamiento efectivo cuando se está trabajando procesos educativos con niños y chicos que ya vienen de hogares donde sus padres siguen los principios éticos democráticos y estos fueron disciplinados a seguir los mismos pasos que ellos.

De forma contraria, niños pertenecientes a hogares ya destrozados por la violencia de todos los tipos, como los abusos físicos, el alcohol, las drogas y el divorcio, no tienden a buscar apoyo en buenas compañías, sino que buscan construir formas violentas de fortalecimiento; lo peor de estas uniones es que los iguales suelen atraerse y, un grupo de sádicos violentos reunido tenderá a producir los peores baños de sangre y nada de esto hará la menor diferencia en sus sentimientos para con el dolor de los parientes de las víctimas o con estas mismas. El colectivo tiene el poder de destruir todo, y cualquier sentido de medida de las consecuencias, será tomado como si las mismas simplemente no existiesen.

Esto prueba que el colectivo ejerce un poder absurdo sobre la mente de las personas, destrozando su capacidad de razonar y reflexionar; además, deja la impresión de que la única cosa que comanda la voluntad es el más poderoso instinto sádico y de búsqueda de felicidad, sin importar más nada. Siempre que cualquier episodio de este tipo venga a su mente será recordado como una aventura en favor de la liberación y de combate a la tiranía. Es un mensaje impregnado en la memoria del adolescente: le dice que combate un mal que de no ser extirpado, provocará insatisfacción a muchas otras personas.

Esta es una lectura a posteriori, porque en el momento de la acción no hay ningún sentimiento más allá de satisfacción, ansia de provocar dolor y una sensación de placer que se aproxima a un éxtasis, la manifestación de una fuerza arcaica reprimida que encuentra libertad cuando está en medio de otros. Es como si el colectivo tuviese el poder de aflojar las cadenas morales del individuo, imposibilitadas así de mantenerlo dentro de límites. Como estamos hablando de criaturas que ya no poseen sensor moral ni ningún parámetro de valor positivo en el que se vea reflejado y se identifique; este se ve reflejado en bandidos clásicos de la historia, del mismo modo como son retratados los personajes infanto-juveniles de la obra $\mathrm{Ca}$ pitanes de Arena (1980), del escritor brasileño Jorge Amado (1912-2001). 
Existe todo un conjunto de tesis para decir que tales comportamientos de estos niños, chicos y adolescentes son la forma que encuentran para mostrar su indignación por sus condiciones de abandono y de miseria social, representando un grito contra la inercia del poder público. Tales discursos solamente favorecen el surgimiento de creencias que ayudan a alimentar la idea romántica de que el colectivo está siempre trabajando por la promoción de la libertad de expresión y del combate al conservadurismo opresor y contra la preservación del statu quo.

Así que, ¿dónde se encuentra el sentido de amor y belleza en tales actos, promovidos por estos colectivos?, ¿dónde se encuentra la libertad de la que tanto alardean? Tomando la concepción de Juan Jacobo Rousseau (1712-1778), expresado en su obra Confesiones (1948), estos individuos son más esclavos que aquellos que están bajo hierros, porque son obligados a practicar la violencia para sentirse señores, para reconocerse unos a otros como individuos de derecho.

Esta es la lógica que impera entre los componentes de colectivos marginales. Existe en el conjunto de bases psicológicas e ideológicas todo este aparato motivacional que conduce a los integrantes a seguir los principios que son dictados por la organización que acaba por transformarse en un valor absoluto, siendo cuestionado solamente cuando no confiere el debido reconocimiento al que el individuo aspira ser merecedor a través de determinadas acciones delictivas. En muy poco tiempo, se pasa a creer que aquello es una verdad, un acto normal sin mayores consecuencias, o sea, el espíritu del miembro se va acostumbrando a toda la conformación, normas y exigencias. De esta manera, se tiene que el chico salió de la condición de anomía: sin embargo, no llegó a la condición de autonomía, siendo esclavizado por métodos de manipulación obsesivos que los confinan en una condición de heteronomía; en consecuencia, debe ser de esta manera para toda la vida porque no consigue vivir como individuo autónomo, no fue educado para actuar así en la vida y el grupo refuerza tal situación por medio de lavado cerebral y condicionamiento del comportamiento.

A partir de lo anterior, es claro que el colectivo ejerce un poder extremamente coercitivo sobre sus miembros y nada se puede hacer para cambiar esto y, lo peor de todo, es que adentro de un agrupamiento de delincuentes las exigencias son impuestas por fuerza para garantizar el espíritu y el principio ideológico del mismo que conducen a los adolescentes a cometer infracciones cada vez de mayor impacto, creando más dificultades para que puedan desvincularse. Cada colectivo, en particular, irá a exigir de sus coetáneos que sea productivo con el mismo porque llega cierto momento en que este gana existencia (casi) propia y a la medida que esto ocurre, en sentido opuesto, aparece un debilitamiento o de la voluntad y del control de la personalidad individual; de manera que este individuo, inscrito en un colectivo, poco a poco pierde su identidad y su yoidad — que ya no eran muy 
sólidas - para ceder a este conjunto de ideas subversivas que están aglomeradas en torno a un proposito, muchas veces, completamente oscuro a los miembros de menor escalón. Cuando se descubren como mano de obra al servicio de los intereses de unos pocos no hay forma de rebelarse porque fue el grupo quien le proporcionó una identidad social, cosa que no pasa sin cobranza por parte del colectivo una vez que este se supone señor de todo aquello que fue adquirido por el adolescente; como no hay posibilidad de devolver la identidad, el coraje, el nombre, el conocimiento de las cosas y de los mecanismos de acción, el precio se eleva y, como resultado, muchos son exterminados al no conseguir huir. A pesar de toda esta violencia fortuita, estos contingentes de infractores no paran de atraer nuevos adolescentes en búsqueda del sueño dorado de ser poderosos y ricos: llegan a ser reconocido por todos a su vuelta como un hombre de respeto, temido por sus enemigos. En sus fantasías psicopatológicas todo sigue un camino rectilíneo y nada se desvía de sus planes originales. El ansia de poder que quema en el espíritu de estos niños-adolescentes puede ser mirado en sus ojos cargados de odio contra todos a los que dirija una mirada.

Este sentimiento expresado por los chicos, interpretado como odio, es una expresión del miedo que sienten de ser privados de todo su poder, porque a pesar de ser neuróticos y psicópatas, no son desproveídos del mínimo de inteligencia y saben muy bien que están en conflicto con los valores sociales constituidos. No obstante, no hay la menor relación de empatía con la justicia, pues esta es considerada por ellos como mala, ya que cuando actúa les príva de sus condiciones de empoderamiento y les impide alcanzar su merecido statu de reconocimiento por sus acciones. Esta es otra explicación para comprender el porqué los chicos delincuentes odian la policía. Ella tiene como principio mantener el orden, sin embargo, para los infractores lo que hace es impedir sus situaciones de goce; un goce cínico, siniestro, acompañado de una necesidad imperiosa de sentirse reconocido, mirado, respetado, símbolo de amor y odio.

En medio de toda esta coyuntura se va cristalizando el sentimiento de conformidad de la población con las situaciones que se repiten indefinidamente hasta el momento en que es tratada como algo normal, meras manifestaciones de los tiempos modernos. A medida que las personas de bien se van acostumbrando a la violencia simbólica de tales grupos, estos mismos van ganando fuerza y dominando el espacio donde el Estado se muestra poco eficiente, actuando como protectores, conquistando la confianza y la credibilidad de las comunidades locales, en un proceso criminal de virtualización de los derechos constitucionales que deberían ser garantizados y ejecutados por el Estado por medio de acciones policiales ostensivas y otros agentes de la justicia encargados de aplicar las leyes y sanciones, de acuerdo con la infracción cometida. 
Fue creada, a lo largo de mucho tiempo, la creencia de que los colectivos marginales surgen como forma de ocupar un espacio abierto dejado por la inacción del Estado de Derecho. Si así fuese, ¿por qué están siempre reclutando chicos y chicas y adolescentes para hacer parte de tales movimientos? O sea, individuos con baja capacidad de análisis y entendimiento de las circunstancias políticas que mueven los más profundos y oscuros intereses. Generalmente, una condición para ser aceptado en estas pandillas es estar fuera de la escuela. Tal situación de vulnerabilidad no debería ser considerada en el proceso de reclutamiento, lo que ya deja transparente que el discurso es, más allá de mentiroso, doctrinador y engañador. Se desea mano de obra que atraerá pocas interrogaciones cuando sean descartados. Con el pasar del tiempo todos pasan a creer que todo este aparato comienza a ganar rumbos de verdad, porque la omisión del Estado tiende a crecer y a ser manipulada por individuos sin escrúpulos; las obras de caridad ejecutadas por los colectivos tienden, en contramano, a ganar expresión, conduciendo a toda la población a un silencio forzado, en primer grado, después de conveniencia, en un segundo momento. Así, el héroe para el niño pasa a ser aquello que es marginal, que es buena plaza, que ayuda a todos a combatir el hambre, el frío y promueve la seguridad. Hacer parte de su colectivo es sentirse realizado.

En el ámbito jurídico la expresión colectivo tiene un concepto formal, siendo construido y fundamentado en el puro interés de ser una organización poderosa que no admite interpretaciones de valor fuera de aquellas que son dirigidas por el comando de la pandilla. En este contexto, la fuerza del grupo se caracteriza y se fundamenta por medio de la negación de la afectividad entre los miembros y el leitmotiv en estos agrupamientos es la violencia explícita aplicada de manera ejemplar sobre aquellos que violan alguna regla, la menor que sea.

Esta condición de ferocidad con que son administrados los colectivos de delincuentes se debe a que sus deseos son volátiles y si así no se garantiza el control, todo se transforma en un tremendo desequilibrio, un caos que ninguna persona puede descifrar cómo va a terminar o qué rumbo tomará. No se puede ceder ante la idea cándida de que los grupos colaboran con el orden de niños salvajes que sueltos irían provocando más desorden, miedo y pavor en la población que bajo una disciplina que los mantiene centrados. Delincuente es delincuente en cualquier situación, su código de conducta y de honor no cambiará por medio de su sensor ético, porque esto es una cosa que no poseen. Ellos solamente conocen la fuerza bruta y el miedo. Son monstruos; y la única cosa que un monstro respeta es otro monstruo más feroz que él. En pocoe tiempo subliman este miedo, convirtiéndolo en admiración y respeto, pero, en las bases hay algo más perverso que es la voluntad de substituir al comandante por la figura de represión que representaba el padre; esta fue transmutada para este objeto simbólico. Otra cosa más atemorizante es que demostrar 
miedo por los jefes es un peligro desmedido, porque estos saben muy bien que un individuo poseído por miedo es capaz de agredir y matar, por precaución y forma de preservar su propia vida.

El entendimiento de los elementos que consiguen servir de eje de articulación dentro de un colectivo, se hace sumamente relevante porque permite aproximarse a una comprensión sobre cómo se consigue sobrevivir en medio de un ambiente donde no hay un vínculo afectivo ajustado a los moldes conocidos por la sociedad de bien. La relación de vivencia y de convivencia interna de estos grupos son muy desequilibradas, pues es un conjunto de personas en búsqueda de algo que no conocen realmente, sino que sienten; esto se debe a que no recibieron una preparación que les permitiera vivir y convivir de modo auténtico y autónomo, no tuvieron ningún tipo de orientación disciplinar.

Este tipo de deformación es un componente esencial para el reclutamiento de nuevos miembros para los colectivos de delincuentes. Sin una dirección preliminar, aquella que les es enseñada será aprehendida como la verdadera, hecho que colabora en el proceso de adoctrinamiento, ya que que no hay nada con que puedan contestar a los valores insertados por los marginales de carrera. Exigen un cuidado muy amplio por parte de la pandilla porque como son chicos sin una cuna que les garantice un soporte afectivo no son capaces de construir lazos con ninguna persona, estando siempre en la zona oscura de un sentimiento desconocido, es decir, no son confiables, bajo ninguna hipótesis. Esta sensación de desconfianza, de un lado, y de inseguridad, del otro, son causas constantes de conflictos sangrientos dentro de los colectivos; estos terminan con muertes prematuras inconsecuentes de muchos chicos. Muchas ocurren por motivos fútiles como envidia, celos, miedo de ser preferido en la ascensión a las cadenas mayores de comando en favor de otro que ha demostrado mayor eficiencia en los trabajos de campo, deudas, hurtos, vicios y substitución sumaria.

Así que, la búsqueda por el reconocimiento colectivo por adolescentes infractores es una condición muy desequilibrada porque, al mismo tiempo en que es un deseo latente que tiene ansia por expresarse, el adolescente vive bajo el miedo de que este deseo sea mal interpretado por sus compañeros que están en posición de comando o por encima de ellos en la jerarquía. Esto genera sentimientos de aprensión y como no conoce la diferencia entre una inseguridad repentina y un miedo caracterizado, tal situación lo conduce a pensar en tomar actitudes drásticas. Esto produce climas austeros que imposibilitan, de manera definitiva, la convivencia entre los coetáneos.

El colectivo no es un espacio pedagógico; no se puede crear la idea romántica de que allí el adolescente que no experimentó ningún principio de formación moral de parte de sus familiares, que jamás fue acogido por sentimientos de amor, afecto, relevancia para sus padres y hermanos, po- 
drá encontrar tales elementos intangibles junto a otros que, igual o peor que él, aprendieron solamente a sobrevivir por medio del uso de la fuerza bruta desmedida sobre sus adversarios, reales o imaginarios.

Esto prueba que se unieron atraídos por las desgracias comunes; en sus condiciones más mediocres de intelectualidad, saben con transparencia que no hay nada de bueno o reconfortante que puedan venir a aprender en medio de tales personas. Sin embargo, el discurso libertador (sic) elaborado por la izquierda puso a todos bajo la condición de oprimidos y alardeó que todas las oportunidades viables, garantizadas por ley para todos, fueron cercenadas a estos individuos, de manera que ellos deberían conseguirlas por medio del uso de la fuerza bruta y desmedida. De esta manera, tales grupos se continúan a proliferando y las familias no los apoyan; no obstante, hacen vistas gordas de sus existencias y actitudes.

El Estado se ha tornado cada vez más impotente ante estos colectivos porque, para empeorar, la escuela y todo su séquito de agentes esclarecidos (sic) (profesores, maestros, directivos) han adoptado la ley del silencio cuando en su presencia se dan las charlas entre los estudiantes y no intervienen; o cuando ejercen influencia sobre la formación de tales conjuntos de trombillas, exaltando la postura de liderazgo de algún alumno mismo y percibiendo que las intenciones no son la práctica de actitudes morales que puedan conducir a la legitimación de la democracia. En este aspecto son culpables por omisión.

El simple acto de desear obtener reconocimiento del grupo en el que convivió, por medio de un imperativo inconsciente neurótico ya puede ser caracterizado como una enfermedad mental grave; este tipo de individuo no se encuentra entre los más fuertes, por tanto, su condición de necesidad de la mirada ajena es una respuesta a su miedo intrínseco de no alcanzar espacio entre la naturaleza y crecer. viene a ser nada más que un objeto condenado a vivir al margen de la existencia social.

Este miedo inconsciente se transforma en miedo inconsecuente, haciendo que el chico se vuelva un objeto altamente manipulable para sus comandantes, toda vez que él estádispuesto a hacer cualquier cosa para ser miembro reconocido dentro del colectivo. Tal actitud lo condiciona a ser un mero objeto que se usa y después de desgastado, sin utilidad, dejar fuera y como forma de manipular la fidelidad y el compromiso de trabajo con el grupo una y otra vez alguien es eliminado, bajo la mirada de todos, bajo acusación de algún tipo o porque no estaba produciendo lo suficiente, como por ejemplo, haber fallado en alguna misión considerada importante. Otras veces, esto es hecho como forma de demostración de la personalidad inflexible e inexorable del comandante de la pandilla; un aviso para aquellos que estaban pensando o que, en algún momento, podrían venir a pensar en atentar contra la autoridad suprema del colectivo. 
Por esto afirmamos que el colectivo no es un espacio característico de promoción de libertad, más bien de extrema opresión y presión psicológica en donde todos son manipulados bajo una distorsión de toda la capacidad de control mental del individuo. En muy poco tiempo, el aprendiz de trombilla es una figura peligrosa no desde el punto de vista de la potencialidad de agredir físicamente a las personas; sin embargo, sí de ejercer dominio sobre sus mentes, utilizando sus propias condiciones de miedo y pánico. Fue transformado en un sociópata, y para llegar a ser un psicópata el paso siguiente es la acción continua de aplicación de sus estrategias de intimidación, ampliando con el pasar del tiempo el círculo vicioso de leyendas que cada vez que son recontadas se enriquecen con nuevos componentes de crueldad y de poder, porque la sociedad floja y cobarde se alimenta espiritualmente con toda esta manifestación empírica de violencia gratuita. El colectivo de marginales y sus ataques en bandos permite que la melancolía que el hombre civilizado guarda de sus días como criatura salvaje sea satisfecha. El psicópata alimenta el deseo reprimido de todo ser fuerte, independiente, macho y superior.

Entre los grupos de delincuentes, aquellos que son novatos en el medio deben demostrar que tienen talento para las cosas nefastas, exigiéndoles que hagan cosas que desafíen la audacia y el coraje, pero, en tales acciones están siempre acompañados por un observador, alguien mayor que él, que hará una relatoría al jefe inmediato acerca del desempeño del candidato. Este primer contacto con las organizaciones no dicen que esté en condiciones de ser reconocido como un miembro, solamente que está en situación de ser aceptado o no en el grupo que más tarde podrá llamar el colectivo.

Esta es una condición muy estresante para el neófito porque no sabe en qué medida debe actuar con más o menos agresividad; entre los grupos de marginales existe todo un equilibrio de fuerzas a ser impuesta, siendo, de una manera esdrújula y un tanto misteriosa, necesario el control del estadio de sadismo que toma cuenta de estos adolescentes cuando en sus bandos actúan contra sus víctimas indefensas. Este respeto (sic) hacia las presas no es porque sean buenos o porque tengan alguna consciencia, misericordia, clemencia; la situación es que mucha violencia genera la atracción de las fuerzas policiales, acto que coloca los negocios en riesgo; la otra parte más siniestra es que la víctima debe ser abordada, siendo molestada en sus derechos de ir y venir bajo un entorno seguroy, aun así, ser agradecida por no sufrir mayores daños.

Se trata de un entrenamiento militar con fines de implantar el terror absoluto, todo planeado para que pueda conquistar y violentar a la víctima; el adolescente que acaba de ser aceptado en el bando muestre lo que es poder, lo que es control y, como él es nada más que un analfabeto sin la menor capacidad de cualquier potencialidad de análisis sobre situaciones simples y complejas, toma aquello como una lección de amplio valor ca- 
racterístico acerca de la personalidad humana, sus motivaciones, acciones y reacciones en situaciones de peligro extremo. Todo parece muy simple: es una demostración del poder del líder del colectivo sobre los neófitos; una vez que representa un grupo de enfermos mentales, el jefe descubre que debe mantener su autoridad mediante el respeto, la admiración y el reconocimiento de sus subordinados, además, él también necesita mantener su vanidad saludable, considerando que, como los otros, es un débil mental que encontró en la delincuencia una forma de sentirse bien.

En el momento enque sea admitido entre los compañeros, el individuo debemantener los anhelos de ascensión muy bien guardados, ya que esto puede ser comprendido por los superiores como una posible traición en algún momento futuro cuando ocurran las luchas por poder dentro de los colectivos. Así, el neófito, que se siente entusiasmado por hacer parte de un grupo que, de alguna forma, le confiere statu y seguridad debe ser entrenado por algún maestro para que se mantenga dentro de ciertos límites muy estrechos y peligrosos de ser rotos; en caso de que ocurra, la sentencia es la pena capital. Miedo y desconfianza son los únicos sentimientos reales dentro de los colectivos; detrás de toda aquella pose de sujetos duros hay un cobarde al extremo, que manda matar sus desafectos y sospechosos como forma de garantizar una vida sin fantasmas. Por tanto, sostener este deseo de ser reconocido por un colectivo de marginales delincuentes es una tarea dispendiosa desde el punto de vista económico psíquico para el adolescente, pues está siempre bajo el juicio de personas que viven con miedo de todo y de todos. Por este motivo, crean ritos de pasaje que desafían cada vez más la capacidad de control psicológico;es un absurdo difícil de imaginar porque ¿cómo que un individuo sin ninguna preparación psíquica consigue mantener una postura ante situaciones desafiantes que posibilitan el despertar del monstruo insano y hambriento que vive libre en su espíritu?

Es un desafío muy amplio para quien no conoce el elemento de que es víctima, porque desea ser reconocido por un grupo, por sus coetáneos, por un colectivo; sin embargo, no sabe qué es esto porque jamás lo presenció en su propia dimensión individual; tiene una idea a partir de lo que pudo presenciar en situaciones de convivencia con sus padres, amigos y otros en extrañas condiciones y ocasiones. El único sentimiento que conoce, con propiedad, es el menosprecio, luego, traduce, en su mente perturbada y caótica, que el reconocimiento sea lo contrario de todo lo que sufre; es obligado a sentir algo que está fuera de su esfera de comprensión psicológica y a interpretarlo como algo positivo, sin importar de dónde venga ni de quién proceda, mucho menos los intereses ocultos en toda esta panacea, porque el dolor de sentirse nadie, aprisionado en un vacío existencial, lleva al adolescente a buscar cualquier cosa que, de alguna manera, pueda rehenchir ese espacio ocioso que lo incomoda tanto. Siendo así, cualquier sentimiento ofrecido por este agrupamiento es aceptado como objeto de 
valor, una especie de satisfacción cínica, una medida de afrontar la vida reglada, limitada al extremo, incapaz de proporcionar gloria, lujos y libertad.

Todos los que ingresan en el mundo de la criminalidad alimentan un gran sueño, que es el de ser el jefe del grupo; sin embargo, debe mantener este deseo oculto de sus compañeros, porque esto es de mal presagio y se debe a que dentro de los grupos criminales organizados o no, solo hay dos modos de ascensión al tope de comando de la cadena: por muerte al jefe en confrontación contra rivales o la policía o incluso por muerte natural. Esto dista del mundo real y todas estas posibilidades ocurren con poca frecuencia, debido a la gran cantidad de capos que son reclutados en todos los tiempos y enviados para hacer el trabajo sucio. Así, el individuo que anhela obtener reconocimiento del colectivo donde esté asociado debe poseer un nivel de educación y control sobre sus impulsos que extrapola sus condiciones de formación personal, porque, a pesar de que fue disciplinado, por su familia, la disciplina recibida no fue suficiente para que formase lazos afectivos con algún otro ser humano que lo haga mantenerse dentro de este espacio de respeto. De forma que la actuación dentro del grupo pasa a obedecer a criterios empíricos, concretos y no abstractos, a pesar de haber toda una propaganda ingeniosa y engañosa que busca crear una impresión de que existe un equilibrio natural entre los miembros, de respeto mutuo, como si las cadenas jerárquicas fuesen construcciones elaboradas por una fuerza sobrenatural para la cual todos deben obediencia incontestada.

Con todo esto se acrecienta la convivencia de toda la sociedad con el crimen organizado y en especial la simpatía que se deja nacer con relación a los menores infractores como si estos fuesen víctimas eternas de un sistema opresor. Podría hasta ser el momento en que fue reclutada por una pandilla y entrenada para fingir que es un producto de la desigualdad generada por la doctrina liberal económica. De ahí para adelante será siempre una figura maleante, inocua, incapaz de sentir cualquier tipo de sentimiento afectivo sincero por alguien, estando en alerta máxima, dispuesta a atacar toda vez que tenga oportunidad o que sea contrariada en sus ansias.

La condición más peligrosa dentro de todo esto es que como el adolescente no conoce lo que son sentimientos de afecto, de pertenecer a un grupo que lo direccione para el camino de otros sentimientos altruistas, él se acaba tornando, dentro del colectivo como una figura de manipulación obsesiva de los líderes, objeto de explotación, viviendo en condiciones de esclavitud, todo esto en nombre de ser mirado por algunos otros que son tan o más decrépitos que él mismo, y en este conjunto de cosas, termina insertado en un círculo vicioso en el cual no hay salida, una vez que se esté adentro porque a cada infracción cometida más parte del grupo se siente y más su sensor de enjuiciamiento acerca de las situaciones que lo involucra va siendo amortecido. 
La coyuntura grupal permite que se despierte un sentimiento de fuerza irracional en que el fin justifica los medios, pero, ni el mismo chico involucrado es capaz de hacer tal lectura de sí y de sus actitudes. Es algo como si la bestia que reposaba en su espíritu tuviese licencia para cazar; las cadenas fueron abiertas lo que ayuda a explicar el porqué de muchos asesinos adolescentes cuando rendidos no demuestran la menor señal de pesadumbre por sus crímenes, y aún se dicen inocentes o que no sabía lo que estaba haciendo. De una manera un tanto extraña, puede ser que él esté diciendo la verdad sobre su inocencia, sin embargo, cuestionarle si sintió placer durante su acto en el momento que su víctima agonizaba entre la vida y la muerte la respuesta tendrá asustar y causar ojeriza.

De la misma forma que el cazador salvaje se sentía en éxtasi [casi tántrico] al abatir su presa después de muchos días de persecución, sintiendo deseos de morderla en cuanto moria sintiéndose un súper hombre, poseído por deseos sexuales intensos, así es el chico que se acostumbra con la caza en la selva de piedra; los sentimientos expresados son de la misma intensidad y de la misma manera que el cazador monstruoso anda en bandos, porque la fiera es más robusta que él, los adolescentes también, porque solos y desarmados son unos maricones, no saben ni hablar derecho, son criaturas abandonadas a su propia suerte; no son nada. Los encuentros siguientes son para rememorar los gritos de socorro dados por la víctima, sus pedidos de misericordia; estas memorias son como los trofeos otrora exhibido en las paredes del hogar de un cazador de safari.

Motivado, impulsivamente, por tales historias su ansia de pertenecer a un colectivo llega a cegar al adolescente que pasa a sentirse como alguien y además alguien importante, que tiene poder y que puede cambiar su vida, ahora que está como miembro de un colectivo que le confiere soporte psicológico. Esta es la creencia más absurda que domina la mente del individuo, ofuscando un entendimiento real sobre quién es, de facto, y cuál es su destino de ahí para adelante. Para él nada de esto tiene sentido porque no fue dotado con la capacidad de pensar abstractamente, no reflexiona sobre sus actitudes porque no hace planes para el futuro; el pasado es una zona oscura que prefiere negar y el porvenir es tan incierto cuando su existencia entera siempre fue; de manera que solo existe el hoy, el momento presente que debe ser disfrutado y vivido en su máxima plenitud.

Esta posibilidad de todo poder, de no haber límites para satisfacción de los deseos funciona como una condición muy seductora que posee un doble sentido: atraer nuevos aspirantes para el grupo y, al mismo tiempo, esconder las verdaderas intenciones de los miembros que son nada más que explotar la fuerza de trabajo y la inimputabilidad criminológica que les es garantizada por la ley. Esto se caracteriza como la peor forma de abuso contra la infancia ya practicada en toda la historia de la humanidad; transformar niños y niñas en piezas de maquinaciones crueles con fines 
de proporcionar garantías de lujo y lujuria, en nombre de reconocimiento. Por esto es que cuando estos infelices descubren que por toda su vida no fueron nada más que objeto de explotación, que sus admiradores y líderes no son mejores ni peores que el sistema carnicero que juzgaban combatir se transformaran en criaturas terriblemente desmedidas en sus acciones, verdaderos suicidas insanos. Esto ocurre porque en su último reducto de salvación solamente encontró miseria y desolación espiritual, dejándolo inerte en medio del vacío, al nada, sin una dirección, sin una referencia.

En esta rama, que se tornó en un negocio, los individuos son descartados después de determinado tiempo de uso, como se hace con una pieza usada que no sirve para más nada. Hacer parte del colectivo no es garantía de ser parte del mismo. Sin preparación psicológica para vivir aislado terminan sus carreras como viciados incorregibles, abandonados a su propia suerte o al azar de la vida, porque ni los mismos familiares los aceptan de vuelta al hogar ni tampoco los socorren. Porque el deseo más profundo de sus parentelas era que hubiese muerto o que no hubiera nacido.

Cuando los adolescentes demuestran el deseos de hacer parte de un determinado grupo de delincuentes, esto parece ser una decisión muy personal y autónoma, facto que engaña a los menos preparados para comprender cómo funciona la mentalidad administrativa moderna del mundo del crimen. Estos que desean hacer algo para ser reconocidos como criaturas importantes ya están siendo observados por aliciadores de menores, conduciéndolos para un extracto del mundo que solo conoce un camino, que es aquello de ida, porque no hay vuelta y tal cosa ocurre no porque hay los juramentos, las decisiones y otras cosas más; es porque la condición de adrenalina y endorfina producidas son algo que conduce al joven al éxtasis, a un estadio de espíritu para más allá del supra normal, una sensación de poder alucinógeno en que él mismo se mira reconocido por todos como un individuo muy poderoso. Y junto con esto hay todo un complejo arrodillamiento en torno del neófito para que sus fronteras mentales sean derribadas y él ya comience, desde muy temprano, a creer que es quien cree que es, porque este era su destino.

Esta es una parte de la psicología del adolescente que el submundo aprendió a explotar con mucha pericia y audacia. Las familias motivadas por una nostalgia de un tiempo político diferente en que los jóvenes comenzaban a trabajar desde edad muy temprana y confrontados por un momento en que las leyes protegen la infancia y la adolescencia de la explotación del trabajo esclavo, y junto con esta medida protectora impide, también, que el niño y el muchacho realicen labores que podrían ayudarles a crear gusto y un vínculo por una profesión decente permitiendo nacer y producir doctrina corporal junto con responsabilidad social, se pierden en el momento de motivar a los hijos a buscar recursos con fines de ayudar en la manutención de la casa y del sustento de los hermanos menores; 
haciendo analogía entre estos dos momentos históricos, la conclusión a la que llegan es que los adolescentes y los jóvenes modernos son perezosos, sin una visión de futuro, acomodados, por tanto, no merecen respeto por parte de los adultos, no los reconocen como sujetos de derecho. No miden las consecuencias de tales acciones y palabras sobre el espíritu de sus hijos que no tienen ninguna culpa, por menor que sea, si los políticos de su tiempo modificaron las leyes, ampliando sus derechos, con esto, confiriéndoles oportunidades que no tuvieron a sus padres en sus respectivos momentos de infancia, adolescencia y juventud. El problema surge porque es, exactamente, en este espacio abierto en la estructura social ideológica que los reclutadores de nuevos soldados para las fuerzas de la delincuencia van a actuar con más persistencia. No llegan ni hacer fuerza excesiva para atraer tales víctimas inocentes para los mundos del tráfico, de la prostitución y de la violencia porque como en estos nichos la vigilancia de protección a los derechos conferidos a la infancia y adolescencia no actúa, no hay ningún impedimento legal, ni sanción para quien los recluta porque una vez capturados por las fuerzas de control policial quien irá a responder por los delitos y/o crímenes es quien esté practicándolos, no su incitador o jefe inmediato de la cadena.

Esta violencia planeada contra los chicos en condiciones de abandono familiar y vulnerabilidad social va creando un círculo vicioso de criminalidad en que los adolescentes llegan a las prisiones como batidores de carteras, acusados de pequeños hurtos y retornan después de cumplir su pena socioeducativa como ladrones profesionales que, a cada regreso al mundo del crimen y al mundo de la prisión, respectivamente, se tornan más y más peligrosos para la sociedad, ya que la formación que reciben, de facto, dentro de los centros es la de sociopatía, de bandidaje superior. Las niñas son desfloradas, precozmente, por los jefes de los colectivos y no demoran mucho para quedar embarazadas, dando origen a más de un delincuente, que dadas las condiciones y situaciones socio familiares de abandono que lo aguarda, será meramente, uno más para el mundo de la criminalidad.

Todo el esquema funciona como una gran red, una mafia, en donde las personas se lucran con ganancias exorbitantes gracias a la delincuencia juvenil y todo su ciclo vergonzoso de manutención por medio de producción de nuevos miserables sociales que serán en el futuro reclutados por las cuadrillas cada vez más organizadas y perversas en sus actuaciones sobre los niños, niñas y adolescentes. No existen el menor grado de escrúpulos entre aquellos que están a comandar estos colectivos, todos los muchachos y muchachas son objetos, cosas con plazos de validad que, una vez alcanzado su tiempo de utilización, serán descartados, no teniendo como responder en contrario; el descarte es automático, siendo substituido por alguien en mejores condiciones de atender a las necesidades económicas del grupo. Esto genera un estadio de ansiedad absurdo en los chicos porque jamás saben cuándo están produciendo el mínimo nece- 
sario exigido para su manutención en el colectivo. Es una ruleta rusa, los ponen bajo una presión excéntrica que es transferida para la población que se torna, indirectamente, víctima de tales sistemas opresores.

La adolescencia, por sí sola, ya presenta conflictos de orden psicológico con relación al cuerpo, al poder de acción y a las limitaciones impuestas por los mayores; todo adolescente cree, ciegamente, que su proyecto de vida es capaz de revolucionar todo el contexto en que esté involucrado. Este sentimiento complejo de superioridad es para enmascarar un sentimiento complejo y vergonzoso de inferioridad, de inutilidad. Generalmente, se siente como una pieza fina no utilizada, facto que hace surgir la revuelta y la indignación por parte de estos individuos. Es en estos momentos de conflicto con el mundo exterior, estos que jamás resuelve que acaban por interiorizar la idea de que es imprestable, así que, inician actitudes de agresión contra sí mismo, una vez que no tiene utilidad para nadie.

Estas criaturas depresivas terminan siendo presas fáciles para hacer parte de colectivos de delincuentes, porque están en búsqueda de un sentido para sus vidas, no son chicos desolados, pertenecen a otro grupo de individuos que poseen familias estructuradas, bien formadas, estudian en buenas escuelas, viven en buenos barrios, con buena vecindad. Su principal problema se encuentra en su autoestima que es baja, llegando a proximidades muy peligrosas de depresión y sus padres no lo perciben, porque creen que la vida buena y confortable que condiciona a sus hijos es suficiente para que sean personas felices y realizadas emocionalmente.

El colectivo familiar debería ser mucho más poderoso que cualquier otro grupo fuera de este círculo, siendo capaz de proporcionar toda la expectativa y fuerza necesarias para el desarrollo normal de los chicos. Infelizmente, no es esto que se ha tenido la oportunidad de asistir; cada vez más hijos y padres se tornan personas extrañas, distantes bajo el perfil afectivo y cuanto más se adelgaza el colectivo familiar más se fortalece el colectivo de pandillas con sus propuestas osadas, milagrosas, llenas de ideales libertarios, todo un aparato que encanta por todas las posibilidades que son presentadas.

Cuando un muchacho es aceptado como miembro de un determinado colectivo tiene en su mente la idea fija de probar a un ser imaginario que es capaz de hacer revoluciones y desea, en mayor grado, probar a aquellos que lo detractaron que es un hombre de mucho poder y potencialidades. Surge, en este momento, el prototipo del futuro monstro para la sociedad, porque en su mente psicótica no hay nada que pueda hacer que supere o elimine de su memoria las palabras de aquellos que no le confirieron el debido reconocimiento. Esta ansia será siempre un objetivo utópico, imposible de ser alcanzado y además superado por la mente doliente del adolescente, facto que conduce a un estadio cada vez más avanzado de acciones delictuosas y/o criminosas. 
A medida que comete pequeños delitos y consigue salir sin ser capturado comienza a creer que es muy bueno en sus acciones; con el tiempo pasa a cometer crímenes cada vez más graves y de mayor impacto en la sociedad. Todo esto se va transformando en aventuras, algo que se realiza por no tener un quehacer, una manera de rehenchir el tiempo ocioso; en un periodo, relativamente corto, las actitudes se van metamorfoseando en estilo de vida que se caracteriza, a posteriori, en necesidad para sentirse bien y realizado.

\section{CONCLUSIONES}

La existencia de tales colectivos de delincuentes condenó todo el trabajo educativo, político y cultural a una oscuridad sin precedentes en donde los valores promulgados por ellos son más atractivos, desde el punto de vista de vivir el momento presente. La postura moral es lanzada por tierra, simplemente, con el intento de atraer niños y niñas que no son más que presas fáciles capturadas en telarañas, después de que son insertados, toda una realidad cruda y perversa es presentada, y la más ínfima actitud de confrontación con la ley establecida es interpretada como una falta de respeto punible con punición ejemplar, para que otros no sigan el ejemplo y en poco tiempo sea costumbre. No hay libertad, y el reconocimiento que tanto fantaseaba es un producto proporcional al desempeño entre sus coetáneos. Ahora bien, ¿qué factores cognitivos e intelectuales llevan a conducir a los adolescentes a este tipo de infierno existencial?. La omisión de la sociedad tiene representado uno de los peores elixires para que los colectivos de delincuentes ganen fuerza y se amplíen. La vida es cada vez reducida a ambientes virtuales en que las personas enmascaran sus existencias llenándolas con flores y caprichos psicóticos que contribuyen para que todo este estadio de degeneración humana se torne el más real posible. Con esto, la sociedad y las personas, individualmente, tienen perdido sus identidades, facto que los impulsa a buscar una imagen de equilibrio en cualquier pedazo de espejo roto. Luego, si la sociedad y los adultos que son el espejo en el cual la juventud busca mirarse, se encuentra roto o sin una textura poderosa, su destino es perder potencia para otros grupos subterráneos que demuestren tener tales calidades tan necesarias para la formación de la personalidad adolescente.

El deseo de ser reconocido por un grupo hace que el individuo abdique de sus valores personales más fuertes, como por ejemplo, su identidad individual, al menos en apariencia, solamente para ser parte de un todo que, en muchos casos, no hace nada más que explotarlo hasta el límite de sus fuerzas. Sin embargo, permanece vinculado a tales usurpadores motivado por una creencia vacía de que es admirado por el jefe, un tipo oscuro de transferencia del padre sanguíneo para este individuo que es colocado como un sucedáneo de Dios-Padre.

Una vez que la personalidad del adolescente haya sido contaminada por los valores antípodas del colectivo, de allí en adelante solamente sufrirá 
deformaciones en su carácter, en donde sus códigos son la depreciación y la depravación de los sistemas de protección a los ciudadanos de derecho. Cuanto más se mira en la figura del jefe del colectivo más perverso se va tornando, guiado por una ética que no es capaz de conducirlo a los caminos de justicia y de la verdad. Si no era nadie antes de ingresar al grupo, ahora mismo es quien perdió su chance de tornase alguien, porque nada que sea propuesto por sus coetáneos tiene la menor posibilidad de proporcionarle estructura cognitiva e intelectual para subsidiarle en la construcción de su personalidad individual. Un colectivo de delincuentes será siempre un colectivo de marginales, ningún proceso de abultamiento de la inteligencia ocurre a partir de la convivencia entre estos seres, solamente el rebajamiento del sensor moral y la calificación como personas.

Una vez admitido dentro del grupo, el neófito tiene que batallar para alcanzar reconocimiento de sus compañeros criminales, tarea nada fácil, porque son actividades direccionadas que exigen sangre fría y audacia, cosa poco común a un ser humano, y que en tales acciones es cuando ocurren las tragedias de facto, porque la víctima sintiendo la hesitación y la impericia del agresor cree que puede actuar en contra y es en este momento que la traba moral se rompe teniendo como consecuencia la agresión fatal contra un inocente. En el grupo esto es mirado como un acto osado para alguien en su primera actuación en nivel de campo, lo que genera un surgimiento de respeto por él como alguien promisor dentro de la cuadrilla.

Este momento de ascensión es uno de los más peligrosos para aquellos que están llegando, ya que, al tiempo que genera admiración y respeto entre los más acostumbrados con la vivencia, origina celos en este mismo grupo, que pasa a mirarlo como una amenaza potencial directa; el mismo jefe supremo toma el cuidado de buscar respuestas entre sus subordinados más cercanos sobre el neófito, cuidando para que su ansiedad no conduzca a futuras creaciones de problemas directos como prisiones por descuido en las actuaciones delictuosas y mismo el sueño de venir a ser el jefe de la organización. Ocurre que dentro de las cuadrillas existen solamente dos sentimientos comunes entre los integrantes, el miedo y la desconfianza. Es un ambiente nefasto donde todos temen a todos y desconfían de todos, porque las formas de ascensión suceden por medio de violencia fortuita y traición. Además, ser reconocido por el jefe y por los demás miembros es carta asignada de que podrá substituirlo en el comando en cualquier momento, y hay personas allí que ya hacen parte del grupo desde hace mucho tiempo, esperando una oportunidad para asumir el comando.

Como las luchas internas no son motivadas y así mismo combatidas con extremada violencia y control rigoroso, tal energía acaba siendo direccionada para el público común en que los ataques salvajes de los delincuentes acaban por tornarse leyendas, y entre estas asciende determinados niños que se van tornando conocidos por su brutalidad y terror utilizados 
en sus actuaciones. Tales actitudes esconden envidia y disputa interna de grupos criminales compuestos por adolescentes en conflicto con sus mundos interiores, en búsqueda de reconocimiento de sus pares, también, delincuentes, pero, con carrera criminal, los cuales son tomados por estos individuos sin ningún mérito de formación personal como ejemplos de fuerza y carácter, o sea, ejemplos a ser seguidos. Un monstro que se refleje en otro monstro solamente puede venir a tornarse en algo tremendamente perturbado, incontrolable, lo que provoca innúmerables muertes dentro de los colectivos. El miedo que algunos adolescentes pasan a despertar en sus compañeros los lleva a asesinarlo, sin la menor piedad.

Cuanto más el adolescente se va distanciando de su familia más se va embreñado en el mundo de la criminalidad y de la delincuencia, siendo motivado cada vez más por sus compañeros de cuadrilla, tornándose más violento, más sádico, siempre buscando desafíos que lo hagan parecer superior a los ojos de todos. En muchos casos las familias hacen uso de la hipocresía, no importándoles de dónde sus y de qué forma sus hijos consiguen los bienes que traen para sus hogares, diciendo solamente que sus hijos son muy buenos y caritativos, ayudando con los gastos familiares con grandes cuantías de dinero y otros productos oriundos de su trabajo, pero, no revela qué trabajo milagroso es este.

La cosa se agrava aún más cuando el adolescente siente que pasa a ser reconocido por sus familiares en la medida en que los abastece materialmente, sin importar de donde venga. Esto crea una sensación de angustia en el individuo cuando aún llegue a poseer un mínimo de carácter, pero, al paso que el tiempo va adelantando su consciencia, va siendo adormecida y sus actividades inmorales se van tornando parte de una rutina de vida. Hubo una cristalización de su carácter que pasó a ser movido por su ego que, cuanto más estuvo satisfecho en su necesidad neurótica de reconocimiento más se adormeció su consciencia ética, tornando las dimensiones entre aquello que es cierto y aquello que es errado como una línea ficticia, no existente en su ámbito de valor.

El colectivo marginal priva a sus miembros de una de las mayores conquistas éticas de la humanidad que es la posibilidad/necesidad de análisis de la propia vida, este examen que permite tener orgullo de las actitudes o vergüenza por los hechos, y de esta forma mejorarse o perfeccionarse como persona de derecho. Este impeditivo categórico es una herramienta de control absoluto sobre las mentes de los chicos que los prepara para la obediencia irrestricta. Para que algo tan poderoso sea alcanzado sin mucho esfuerzo bélico hay que destruir el pensamiento, la condición de cuestionamiento, el sentido crítico, transformándolos en masa de maniobra. Esto queda evidente cuando estos chicos delincuentes son capturados por la fuerza policial y son interrogados sobre las motivaciones que los conducen a tales actitudes y responden con un sencillo encogimiento de 
sus espaldas. En estos momentos no están mintiendo o escondiendo sus objetivos; están expresando sus mundos interiores tal y cual son, de facto.

Este deseo de ser reconocido por sus pares es un sentimiento que se pierde en las arenas del tiempo, habiendo surgido aún en un periodo en que las comunidades eran bien pequeñas y la batalla por la supervivencia un poco más compleja porque esta ocurría contra animales feroces y de gran porte, careciendo de estrategias de búsqueda y ataques muy bien planeados y coordinados. Luego, el hombre cazador no podría ir muy lejos; así que se une a otros como condición de garantizar su manutención en la lucha contra la naturaleza, de forma que tal sentimiento se fue tornando inconsciente, siendo agregado al estilo de vida las comunidades que se fueron tornando mayores y más populosas.

Cuando mencionamos este deseo inconsciente de reconocimiento característico como una enfermedad en los adolescentes y jóvenes de este siglo no es una cosa fortuita. La sociedad civilizada, teniendo como fundamento la igualdad de todos, destruyó barreras que, históricamente, eran útiles y necesarias para la conformación de procedimientos de aceptación de los menores en los círculos de los mayores, eran llamados ritos de pasaje. Muchos de estos rituales sobrevivieron hasta unos pocos años de nuestra era; sin embargo, fueron retirados de la vida pública porque algunos individuos, se diciendo bien intencionados, consideraron que tales actitudesconstituían selección de unos pocos en detrimento de la mayoría. Antropológicamente, tal condición democrática de igualar a todas las personas en derechos sin la práctica de ningún esfuerzo terminó por hacer con que la sociedad dejase de dirigir a las conquistas de los jóvenes un valor místico, supersticioso, tradicional, representando una pérdida considerable en la formación de la estructura psíquica personológica de los jóvenes.

En nuestra sociedad occidental civilizada auto proclamada pos moderna, los adolescentes llegan a una edad avanzada sin una dirección sobre sus destinos y sin saber qué hacer con sus vidas futuras; ni siquiera se conocen a sí mismos, llegando al extremo de no sí miraren reconocidos en ningún otro ser de un árbol genealógica, que sea sus genitores o progenitores. Mucho se perdió a lo largo de la evolución y de la democratización de todos los procesos de vida en sociedad. Así mismo con todos los avances acerca del cerebro y de los procesos de formación y madurez psíquica del ser humano, todos los resultados fueron siendo aplicados con fines de promoción de grupos de anarquistas que la única cosa que hicieron fue distorsionar la naturaleza primitiva y cruda del hombre transformándolo en un doliente que no se conforma con su enfermedad porque se cree muy sabio, muy evolucionado y superior a todos los problemas que la naturaleza condena a sufrir a los seres vivos. 
Con los avances de las ciencias médicas y psicológicas, fue posible alcanzar un entendimiento bastante amplio acerca del funcionamiento y desarrollo del cerebro humano y, esto solamente quiere decir que se conoce como funciona, no como funciona, de facto, dentro de la cabeza de cada ser independiente. La Sociología, utilizando procedimientos de análisis comportamentales de los grupos urbanos, cruzando sus conclusiones con los resultados de estudios realizados en medio de grupos alejados de la civilización puede llegar a relevantes deducciones sobre los principios que reglen a los individuos. Con esto, desafortunadamente, cometieron el error de considerar que la sociedad civilizada, creó costumbres que necesitaron de conceptos y restricciones a los modos de vida que representaban la buena salud psíquica de los chicos. El fracaso fue catastrófico porque quienes analizaron los resultados y los interpretaron fueron burócratas y otros especímenes, lo que condujo a un entendimiento de que el adolescente civilizado es infeliz y rebelde porque no tiene libertad, está bajo represión de un sistema patriarcal, retrogrado y opresor.

Bajo esta ideología crítico-libertadora, los grilletes fueron destruidos y la tan soñada libertad de pensamiento y de acción fue concedida a los adolescentes y jóvenes, que ahora pueden seguir sus destinos conforme siempre desearon. El problema surgió y se transformó en un grave contratiempo al conceder libertad y librarlos de la opresión, ya que, junto con la destitución de la condición de opresión a la cual estaban sometidos perdió, a su vez, la condición de protección a la cual tenían por derecho natural. Pasaron a ser portadores de una condición para la cual no estaban preparados porque, antropológicamente, no recibieron de la naturaleza tal preparación y en sentido contrario perdieron una condición que es esencial para una buena formación estructural. El resultado de toda esta panacea es una juventud enfermiza, caquéctica, sin una dirección personal, en búsqueda de algo que no sabe bien lo que es, porque no tuvieron educación, no fueron disciplinados, y ni sus cerebro son entrenados para ser independientes. Esto fue otro error de quien acreditó que, para ser felices, los jóvenes deberían ser independientes; no estaba hablando de conquistar independencia y sí de adquirir autonomía, estas que son cosas muy distintas, tanto semánticamente como desde el punto de vista integrativo práctico.

De todo este discurso libertario quienes más celebraron tal evolución del pensamiento fueron las familias que, con esto, entendieron que podrían tirar una carga pesada de sus espaldas, una vez que ahora sus hijos irían a seguir caminos escogidos por ellos mismos, no dependiendo más de sus padres a estar interfiriendo en las decisiones, porque serian suficientemente maduros para saber aquello que quieren o que no quieren, para discernir entre aquello que es bueno o malo. Tal posicionamiento de los padres condenó a sus hijos a un estadio de soledad sin precedentes, dejándolos sin un soporte que pudiese orientarlos en cómo actuar de manera autónoma y/o independiente, considerando que esta última condición es un acto insano de violencia contra los chicos adolescentes. 
Desprovistos de esta autoridad parental quedaron sin un referente que pudiese garantizarles substancia personológica, haciendo nacer una generación completamente perdida y sin saber qué hacer de sus vidas; no saben de dónde vinieron, sus raíces ideológicas, en especial, son oscuras siendo alimentadas con historias surrealistas, fantasiosas [para no decir esquizofrénicas] de victorias sobre autoridades competentes; no saben quiénes son, sin un perfil de identidad; no saben dónde están, no poseen sentimientos de pertenencia con su tiempo y espacio; ni saben para dónde caminar, careciendo de una visión de futuro; o sea, una vez se entreguen a sí mismos, son como ciegos con lamparillas; no les sirven de nada. Esta es una aproximación a la problemática que ha contribuido a la conducción de los adolescentes hacia el mundo de la delincuencia, esto como forma de obtener el reconocimiento de la sociedad. Esta creencia es un engodo contado por un agente manipulador que los hace creer que son poderosos; no obstante, son aislados de las oportunidades por una élite que debería reconocerlos y, una vez que esto no ocurra por el camino del bien debe hacerse por el camino del mal; lo que importa, de facto es que haga, porque tal condición es un derecho suyo, que está siendo negado, por tanto, debe ser rescatado.

Lamentablemente, como no tuvieron ninguna orientación de cómo proceder ante la vida, las dificultades que son inherentes a la vida de todos, agregado al fator de que ningún reconocimiento viene sin una buena dosis de trabajo arduo y un largo espacio de tiempo, estos adolescentes actúan en favor de la satisfacción inmediata de sus deseos, sin importar con las consecuencias inmediatas y directas que puedan tener sobre sí. Este es el estadio deplorable al que la sociedad moderna está conduciendo a sus jóvenes en nombre del empoderamiento, la libertad de pensamiento, la libertad de expresión y de una existencia vivida en su plenitud, y además, es una existencia ausente de cualquier tipo de sanción, fundamentada en el clásico dominio absoluto de la anarquía.

Así que, se tiene una gran paradoja al tratar tal asunto que involucra el deseo de reconocimiento colectivo porque, al comenzar esto que llamo aquí deseo, como si fuese una condición autónoma del individuo adolescente es, de facto, una necesidad del género humano, un sentimiento tan primitivo y tan poderoso que es capaz de llevar buenos chicos a buscar apoyo en grupos extraños. Y, en secuencia, se tiene la otra parte del valor que es la de que el colectivo de delincuentes tiene duras reglas para quien ingresa en su medio, debiendo ser respetadas bajo pena de severas sanciones, en casos de transgresión, o simplemente de no obediencia estricta a las mismas. Esto, por sí solo, ya coloca abajo la idea preconcebida de que el chico adolescente no quiere respetar el orden, porque si así fuese no seguiría el regimiento del colectivo de marginales. Con esto surge una cuestión difícil de responder, pero que abre precedentes para análisis y futuras interpretaciones: ¿Qué tiene de especial el colectivo que hace que los chicos y chicas sigan los principios del mismo sin cuestionar? Es exactamente aquí que presento la paradoja, porque, si seguimos la sabi- 
duría convencional, estaremos aptos para defender con extrema autoridad que está a huir de la autoridad parental que es opresora y represora; sin embargo, los códigos de conducta del colectivo son mucho más severos que aquellos adoptados por la familia y la sociedad; entonces, tenemos que pensar que, a medida que la autoridad parental se fue tornando floja, el instinto primitivo del adolescente tuvo que buscar en otro local y en otra figura alternativa esta autoridad austera, fuerte e imponente sobre sí, como si para formar y consolidar su personalidad tuviese que pasar por tal condición. Hay un punto en que, aunque la severidad del grupo sea más brutal que aquella aplicada por la familiar, el colectivo permite que el individuo haga cosas que sus padres jamás, en sana consciencia, jamás los permitirían. Siendo así, la confrontación entre los dos grupos no estaría en el campo de la autoridad, pero, sobre el valor de cada colectivo, en particular. Por más desequilibrada que sea una familia, los padres jamás permitirán que sus hijos insulten a los otros, en especial a los más débiles, no quedarán muy satisfechos si ellos manifiestan posturas sádicas, mucho menos que los chicos se tornen asesinos o prostitutas, pasando a vivir, en la más completa marginalidad social.

Siguiendo esta línea de pensamiento, parto de aquí para hacer una deducción: el deseo de reconocimiento siendo una necesidad biológica y antropológica inherente a la naturaleza humana, tiene que haber algo más poderoso formado a nivel de sistema límbico, una cosa que, una vez alcanzada va provocar un éxtasis místico, trascendental en el chico adolescente y tal elemento solamente puede ser el deseo de potencia. Esta voluntad de ser poderoso, no es solamente esto, pero, ser El Todo Poderoso, incuestionable en sus actitudes, tener a todos se enrodiando a sus mandos en franca obediencia incontestada es la cosa que parece incendiar el espíritu de los muchachos y muchachas con sensibles alteraciones de acuerdo con el género respectivo.

Es como el medio inconsecuente de alcanzar sus deseos más intrínsecos que se juega en tales aventuras, con una certeza psicótica de que nada puede estorbar su caminar en sentido de la realización de su satisfacción esquizopática. Generalmente, no alcanza tal cosa porque la concurrencia es muy grande, los medios para llegar allí son complejos y peligrosos, facto que hace que muchos desistan, otros sean eliminados y hay aquellos obstinados que desafían desde la suerte hasta la muerte para atingir sus objetivos, que en su cabeza es tratada como una jornada mesiánica; luego, tiene que ser atingida, cueste lo que cueste.

Tan luego alcance este poder que sueña tener para sí, el sacrificio y sumisión a una autoridad austera, opresora y represora estará representada en su memoria como un mero sacrificio que tuvo que enfrentar o hacer para llegar a un determinado fin. Esta comprensión de la mente del chico delincuente permite entender el porqué de su admiración por el jefe de la cuadrilla porque no está a vislumbrar y admirar únicamente el individuo 
que allí se encuentra, antes está mirando el lugar donde desea estar. Este puede ser un motivo que ayude a explicar el porqué de que una vez se ingresa al mundo de la criminalidad no hay más salida; la ecuación no es tan simple, es el propio individuo que no lo deja porque su deseo no siempre es satisfecho y aun así fuese, habrá un problema un poco mayor que se trata de la manutención de tal statu, que igual que él, hay otros que están caminando en la misma línea de deseo oculto.

Entre el deseo y el poder hay una diferencia monstruosa cuando son analizados en cuanto a entidades que pueden proporcionar satisfacción. Con relación al deseo vale la máxima 'deseo satisfecho es igual a deseo instinto'. Podrá surgir otro en su lugar, pero, no más un deseo de ampliación de aquello mismo que acabó de ser sanado. Ya con relación al poder la cuestión es más grave porque el problema con el poder es que esto jamás es suficiente. El deseo de más poder tiende a crecer exponencialmente en la medida que va siendo conquistado.

Cuando el chico o la chica deciden hacer parte de un colectivo de delincuentes su primer deseo es el de alcanzar reconocimiento de un grupo, un sentimiento relativamente simple que, con una buena dosis de acción y emprendimiento en un tiempo bastante corto ya estará satisfecho. Y, es en este intersticio de tiempo que, otro deseo más violento y que no puede ser sanado, comienza a demonstrar sus fuerzas. Este otro, más agresivo y voraz tiende a dominar todas las satisfacciones, y el adolescente entra en un estadio de aceptación de que solamente será alguien realizado cuando alcance determinado puesto de comando dentro de la organización, de modo que, todo su estado de espíritu acaba siendo consumido por esta idea insana, llevándolo a cometer atrocidades hasta contra sus propios compañeros. Es en este punto exacto que nace en su espíritu un nuevo deseo de ser reconocido, ahora como jefe o como alguien que esté preparado para asumir el puesto deseado. Por tanto, tiene que realizar tareas que lo coloque en una posición de comando, actividades cada vez más osadas, que involucren grandes proporciones de peligro directo, pero, que obtenga beneficios para el colectivo, o sea, por más que se acredite libre de la presión grupal, no es más que una marioneta de la voluntad colectiva.

Esto ocurre por el facto de que todo colectivo es formado en torno a una ideología, por tanto, es detentor de una psicología poderosa que gobierna a los miembros y, en mayor o menor grado, todos están sometidos a ella, condición que funciona como un dominio absoluto sobre sus mentes, impidiendo que, en algún momento, abandonen el mismo porque el grupo no sobrevive sin elementos que le permitan tener fuerza, o sea, la fuerza del colectivo es un retorno de la potencia individual unida a otros individuos sobre un único destinatario, por esto, la característica representativa de poder asombroso con que se muestran estos conjuntos de delincuentes juveniles. 
La formación de grupos en adolescentes en la actualidad no es una construcción de los siglos modernos, esto es una característica de tiempos muy primitivos de acción humana que necesitaban unirse delante de la defensa de sus territorios particulares, el honor y la misma caza. Los miembros reclutados para estos contratos tenían edades entre los 15 (quince) y los 25 (veinticinco) años. Ocurrió que, con el proceso de civilización y más tarde con la implantación de los acuerdos de paz, mucha de la agresividad primitiva, tan necesaria y, por veces, definitiva para la sustentación de las comunidades tuvo que ser suprimida, dando lugar al estadio democrático y los enjuiciamientos dentro de tribunales. El proceso evolutivo de la mente humana en dirección a la civilidad y a la convivencia pacífica con sus pares no destruyó el instinto cazador sádico que dominaba el espíritu del hombre primitivo.

Así mismo, entre los adolescentes y jóvenes este sentimiento tuvo que sufrir modificaciones, porque un salvaje ya no disfrutaba de un lugar de prestigio en el nuevo orden social; como ocurre naturalmente una parcela insana perduró, más sencilla, pero, no sin su representación de potencia y deseo de manifestación. Freud (2006) respondió que la personalidad humana fue formada de la misma manera que la superficie terrestre, en donde los sedimentos fueron sobrepuestos a todo lo que existía, es decir, hubo una modificación en la presentación de la forma y apariencia, no en el espíritu primitivo, las emociones, los deseos, las intenciones y la libertad, esto ya explotado en la filosofía nietzscheana.

Cuando, de facto surge este sentimiento imperioso como una necesidad de ser reconocido por sus pares iguales es algo muy difícil de ser precisado, porque el hombre, en sus principios de convivencia todo era muy restrictivo a una vida colectiva que exigía una obediencia ciega a las costumbres de la comunidad. Lo que se puede deducir es que la emoción producida por la caza y la producción de adrenalina y endorfina llevó a este ser primitivo a sentir un éxtasis en las búsquedas lo que fue interpretado por sus compañeros como algo digno de notar, creando en torno del mismo un séquito de leyendas, cuentos, historias, cosa que pasó a despertar en sus coetáneos el deseo de ser visto como aquel guerrero.

No ser reconocido por el colectivo es estar, por extensión, relegado a la exclusión social, porque toda la sociedad que involucra este grupo circunspecto sigue, de una forma, más o menos, imperiosa las ideas que proviene del mismo. Existe todo un mito en torno al agrupamiento, un conjunto de leyendas e historias que son transmitidas como verdad porque están involucradas en fantasías en donde el héroe siempre supera a los enemigos de la sociedad, aquellos personajes que son detestados por todos, en mayor o menor grado, como por ejemplo, la policía y los agentes de seguridad del Estado. 
En este mismo sentido, crean símbolos de representación que provocan el horror en las personas, quienes tienen aversión al mirarlos, porque representan agresividad, fuerza primitiva y caracterizan acciones de violencia contra todo lo que está dado como facto social. Esto acaba por atraer a una cantidad bastante considerable de adolescentes, al comenzar esta fase de la vida hay, naturalmente, un vacío afectivo que carece de ser rehenchido de alguna forma y aquí esbara en el punto de no comprender cuáles son las bases fundamentales que sostienen el carácter de tales niños. Cuanto mayor sea la alienación parental sufrida por tal individuo, proporcionalmente, crecen las tendencias en que ellos buscan agregarse a grupos representados por cuadrillas de infractores, o sea, individuos que confrontan el orden considerado como ideal.

Esto no quiere decir que tengan un plan de acción que pueda cambiar los valores sociales, poseen solamente odio por haber sido relegados a una condición de abandono, de aislamiento afectivo por sus padres, cosa que sugiere que sus acciones son de carácter vengativo contra un elemento característico subjetivo, surreal; sin embargo que alimenta toda una industria de crímenes cada vez más recurrentes. El problema se profundiza cada vez más porque las interpretaciones del mal son hechas de modo superficial y las políticas de enfrentamiento son elaboradas teniendo como fundamento aquello que conviene a los dirigentes presentar como solución práctica ideológica, jamás una solución práctica factual, porque esto iría de confronto con toda una ideología de que el Estado puede ser un bueno administrador de la voluntad social, consiguiendo dominar a todos bajo su autoridad, manteniendo el orden y los principios morales convictos.

Ocurre que ningún otro tipo de afecto direccionado a los niños y adolescentes es capaz de superar el reconocimiento familiar. La familia es un colectivo donde existe un vínculo inconsciente, sanguíneo, formado a partir de valores que garantizan la estabilidad emocional equilibrando elementos antagónicos en la vida humana, que es la disciplina y la doctrina, de un lado, y el amor y la ternura, de otro.

Ocurrió, en algún momento de la historia de la civilización humana que las cosas referentes a la vida en comunidad tuvieron que ser revisadas y en ese momento fueron producidas normas estrictas para cada situación en particular. No se puede caer en el engodo de acreditar que todas fueron producidas con la intención de mejorar la vida del pueblo; las reglas fueron generadas teniendo en mente la posibilidad del jefe del grupo persistir en el comando, evitando que posibles desafectos pudiesen asumir el control de los grupos organizados.

En ese tiempo se produjo la idea de colectivos, pequeños grupos que comandaban las acciones directas de selección de nuevos miembros con leyes y pruebas muy duras para los interesados en hacer parte, algunos 
de estos grupos colocaban espacios temporales bastante largos para la admisión como miembro efectivo del mismo. Esto garantizaba la seguridad del poder central que gobernaba sobre los colectivos y hacer parte de los mismos era tener la expectativa de, un día, llegar al tope de la cadena de comando, o sea, el deseo de poder, siempre estuvo como una pieza escondida en algún lugar del espíritu del individuo que se sujetaba a las condiciones de este grupo.

\section{REFERENCIAS BIBLIOGRÁFICAS}

ALEXANDER, F. y HEALY, W. (1946). Las Raíces del Crimen: Psicoanálisis de los móviles de la conducta criminal. Buenos Aires: Asociación Psicoanalítica Argentina. [Obra publicada, originalmente, en 1935].

ALEXANDER, F. y STAUB, H. (1961). El Delincuente y Sus Jueces Desde el Punto de Vista Psicoanalítico. Madrid: Biblioteca Nueva. [Obra publicada, originalmente, el 1929].

AMADO, J. (1980). Capitães de Areia. São Paulo: Record. [Obra publicada, originalmente, el 1937].

ARISTÓTELES. (2007). A Política. São Paulo: Editora Escala.

BURGUESS, A. (1972). A Laranja Mecânica. São Paulo: Artenova. [Obra publicada, originalmente, el 1962].

CÓRDOVA, H. M. (2008). Factores Asociados y Trayectorias del Desarrollo del Comportamiento Antisocial durante la Adolescencia: Implicancias para la Prevención de la Violencia Juvenil en América Latina. En: Revista Interamericana de Psicología/Interamerican Journal of Psychology - 2008, Vol. 42, Núm. 1, pp. 129-142.

DIMOULIS, D. (2011). Manual de Introdução ao Estudo do Direito: definição e conceitos básicos, norma jurídica. 4. ed. rev., atual. e ampl. São Paulo: RT.

DOSTOIEVSKI, F. M. (2000). Crime e Castigo. São Paulo: Nova Cultural. Obra publicada, originalmente, el 1866].

DURKHEIM, E. (2004). O Suicídio. São Paulo: Martin Claret. [Obra publicada, originalmente, el 1897].

FAIRCLOUGH, N. (2001). Discurso e Mudança Social. Brasília: Editora da Universidade Federal de Brasília. [Obra publicada, originalmente, el 1992].

FOUCAULT, M. (2004). Vigiar e Punir - O nascimento da Prisão. 29. Ed. Petrópolis: Vozes. [Obra publicada, originalmente, el 1975].

FRANKL, V. E. (2015). Em Busca de Sentido - Um Psicólogo no Campo de Concentração. Petrópolis: Vozes. [Obra publicada, originalmente, el 1946]. 
FREUD, S. (2006 [1913-1914]). Totem e Tabu. In: Edição Standard Brasileira das Obras Psicológicas Completas de Sigmund Freud, Vol. XIII. Rio de Janeiro: Imago.

GARCIA, J. A. (1945). Psicopatologia Forense. Rio de Janeiro: Revista Forense.

GOFFMAN, E. (2001). Manicômios, Prisões e Conventos. 7. Ed. São Paulo: Editora Perspectiva. [Obra publicada, originalmente, el 1961].

GOFFMAN, E. (1988). Estigma: Notas sobre a Manipulação da Identidade Deteriorada. Rio de Janeiro: Editora LTC. [Obra publicada, originalmente, el 1963].

GRINDER, R. E. (1976). Adolescencia. México: Editorial Limusa. [Obra publicada, originalmente, el 1973].

GUERRA, A. M. C. e FRANÇA NETO, O. (2012). Laço Social e Adolescência: O Pai e a Infração. In: Psico, v. 43, n. 4, pp. 490-499, out./ dez. 2012.

JASPERS, K. (2015). Psicopatología General. Ciudad de México: Fondo de Cultura Económica. [Obra publicada, originalmente, el 1913].

KANT, I. (2009). Resposta à Pergunta: O que é Esclarecimento? São Paulo: Edusp. [Este texto es una respuesta encaminada al reverendo Sr. Zöllner, en respuesta a la pregunta por él elaborada y publicada en el periódico Berlinischer Monatschrifft, en la fechade 05 de diciembre de 1783, seguida por el comentario que la acompaña: ¿Qué es el esclarecimiento? Esta cuestión es aproximadamente la siguiente: ¿Qué es la verdad? iSe hace necesario responder a esta cuestión para que el hombre se juzgue esclarecido! iY aún no he visto a ningún individuo que haya respondido a esto! El Sr. Inmanuel Kant encaminó su respuesta al periódico el 30 de septiembre de 1784.

LE BON, G. (s.d.). Psicologia das Multidões. Mira-Sintra: Publicações Europa-América, Lda. [Obra publicada, originalmente, el 1895].

LOMBROSO, C. (1983). O Homem Criminoso. Rio de Janeiro: Editora Rio. [Obra publicada, originalmente, el 1883].

LOMBROSO, C. (2010). O Homem Delinquente. São Paulo: Ícone Editora. (Primeira reimpressão). [Obra publicada, originalmente, el 1874].

LORENZ, K. (1973). Civilização e pecado: Os oito erros capitais do homem. São Paulo: Brasiliense.

MAKARENKO, A. (1957). Poema pedagógico. México: Fondo de Cultura Popular. [Obra publicada, originalmente, el 1935].

MALINOWSKI, B. (2008). Crime e Costume na Sociedade Selvagem. 2. Ed. Brasília: Editora UNB. [Obra publicada, originalmente, el 
1926].

MARCELLI, D. y BRACONNIER, A. (1986). Manual de Psicopatología Del adolescente. México: Masson. [Obra publicada, originalmente, el 1984].

MASENS, L. E. M. (2009). Cultura, Identidad y Comunicación: Proyecto Curricular Para el Desarrollo de la Competencia Cognitivo-comunicativa y Sociocultural de los Jóvenes Sancionados en Centros Penitenciarios. Tesis en opción al grado científico de Doctor en Ciencias Pedagógicas. Universidad de Ciencias Pedagógicas "Enrique José Varona". La Habana (CU).

MOSCOVICI, S. (2004). Representações Sociais: investigações em psicologia social. 2. Ed. Petrópolis: Vozes.

NIETZSCHE, F. W. (2004). Para Além do Bem e do Mal. São Paulo: Martin Claret. [Obra publicada, originalmente, el 1886].

PEIXOTO, A. (1938). Psico-Patologia Forense. Rio de Janeiro: Francisco Alves. Obra publicada, originalmente, el 1916].

PENTEADO FILHO, N. S. (2012). Manual Esquemático de Criminologia. 2. Ed. São Paulo: Saraiva.

REIK, T. (1965). Psicoanálisis del crimen - El Asesino Desconocido. Buenos Aires: Ediciones Hormé. [Obra publicada, originalmente, el 1932].

ROUSSEAU, J-J. (1948). Confissões. Rio de Janeiro: José Olympio. [Obra escrita, originalmente, entre el 1764-1770].

SILVA, G. P. e SILVA, J. P. (1933). Crime e Psíco-Análise. Rio de Janeiro: Livraria Editora Marisa.

SMANIO, G. P. (2005). Processo Penal. 3. Ed. São Paulo: Atlas. [Obra publicada, originalmente, el 1999].

WAISELFISZ, J. J. (2015). MAPA DA VIOLÊNCIA 2015. Adolescentes de 16 e 17 anos do Brasil. Rio de Janeiro: Faculdade Latino-Americana de Ciências Sociais - FLACSO.

WILDE, O. (2012). A Alma do Homem sob o Socialismo. São Paulo: LM Pocket. [Obra publicada, originalmente, el 1891].

WINNICOTT, D. W. (2014). Privação e Delinquência. (5. Ed. - $2^{\mathrm{a}}$ tiragem). São Paulo: Martins Fontes. [Obra publicada, originalmente, el 1984].

ZIMBARDO, P. (1971). O Experimento do Cárcere de Stanford. Stanford University.

ZIMBARDO, P. (2012). O Efeito Lúcifer: Como pessoas se tornam más. Rio de Janeiro/são Paulo: Record. 